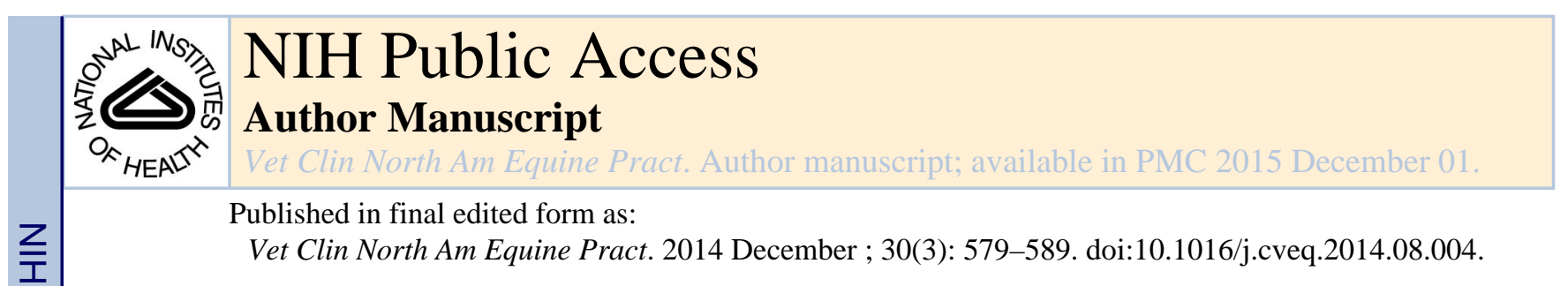

\title{
Hendra virus
}

Deborah Middleton

Senior Veterinary Pathologist, CSIRO Australian Animal Health Laboratory, Geelong VIC, Australia

\section{Synopsis}

Hendra virus infection of horses occurred sporadically between 1994 and 2010 as a result of spillover from the viral reservoir in Australian mainland flying-foxes, and occasional onward transmission to people also followed from exposure to affected horses. For reasons that are not well understood an unprecedented number of outbreaks were recorded in 2011, including the first recorded field infection of a dog, leading to heightened community concern. Increasingly, pressure mounted to instigate measures for control of flying-fox numbers, and equine health care workers started to leave the industry on account of risk and liability concerns. Release of an inactivated subunit vaccine for horses against Hendra virus represents the first commercially available product that is focused on mitigating the impact of a Biosafety Level 4 pathogen. Through preventing the development of acute Hendra virus disease in horses, vaccine use is also expected to reduce the risk of transmission of infection to people. This approach to emerging infectious disease management focuses on the role of horses as the proximal cause of human Hendra virus disease, and may assist in redirecting community concerns away from the flying-fox reservoirs, keystone species for the ongoing health of Australia's native forests.

\section{Keywords}

Hendra; horse; pathogenesis; vaccine; emerging; zoonotic; infectious; disease

\section{Emergence}

Hendra virus $(\mathrm{HeV})$ is a zoonotic paramyxovirus that emerged in 1994 in the Brisbane suburb of Hendra, Queensland, Australia (1). It was the first member to be characterized within a new viral genus Henipavirus in the order Mononegavirales and family Paramyxoviridae, wherein it forms a distinct clade with Nipah virus and Cedar virus $(2,3)$. $\mathrm{HeV}$ was initially isolated from equine lung tissue during investigation of an outbreak of

Crown Copyright $@ 2014$ Published by Elsevier Inc. All rights reserved.

Corresponding author: Deborah Middleton, BVSc, MVSc, PhD, CSIRO Australian Animal Health Laboratory, PB 24, Geelong VIC 3220 AUSTRALIA, Phone: +61 35227 5016, Fax: +61 35227 5555, Deborah.middleton@ csiro.au.

Conflict of interest:

Dr Middleton: Nil

Publisher's Disclaimer: This is a PDF file of an unedited manuscript that has been accepted for publication. As a service to our customers we are providing this early version of the manuscript. The manuscript will undergo copyediting, typesetting, and review of the resulting proof before it is published in its final citable form. Please note that during the production process errors may be discovered which could affect the content, and all legal disclaimers that apply to the journal pertain. 
severe febrile respiratory disease in horses that lead to the natural death or euthanasia of 14 out of 21 affected animals. Two people - a horse trainer and a stablehand - who had close contact with the infected horses developed an influenza-like illness (ILI), and one of these patients died with severe interstitial pneumonia. $\mathrm{HeV}$ was also isolated from the kidney of the fatal human case. On inoculation into experimental horses, $\mathrm{HeV}$ induced a similar disease to that observed in the field; the virus was able to be re-isolated from their tissues including lung, kidney and lymph nodes thereby confirming that $\mathrm{HeV}$ was the etiologic agent of the field event.

There were further sporadic HeV outbreaks in horses between 1994 and 2010, with 14 events identified overall each involving up to five horses; all occurred in coastal Queensland or the north-eastern corner of New South Wales (NSW) (Fig. 1A). Then, over 2011 and 2012, there were $26 \mathrm{HeV}$ incidents in horses including the first case west of the Great Dividing Range (Fig. 1B). Together with discovery of the first field infection in a dog on a property undergoing a $\mathrm{HeV}$ disease investigation (4), these events substantially raised the community profile of $\mathrm{HeV}$ infection as an unmanaged emerging zoonotic disease. The following year saw eight $\mathrm{HeV}$ incidents overall and, for the first time, equal numbers of equine cases were seen in NSW as Queensland. A second canine case was also found on an outbreak property (5).

\section{Zoonotic infection}

There have been five $\mathrm{HeV}$ outbreaks in horses that have been associated with transmission of infection to people, and there is a strong epidemiological connection between infection of people and direct contact with horses. Six of the seven affected humans have been exposed to the blood or secretions of terminally ill horses or have been contaminated with body fluids during post mortem examination of infected horses; three were veterinarians. In the seventh patient, a veterinary nurse, the high-risk exposure was assessed to have occurred while performing daily nasal cavity lavage (for management of another condition) on a horse during the last three days of its $\mathrm{HeV}$ incubation period (6). The $\mathrm{HeV}$ attack rate for people exposed to potentially infected equine body fluids has been estimated at $10 \%$ (6). $\mathrm{HeV}$ infection in people has an estimated incubation period of 9-16 days and is associated with ILI that can progress to encephalitis which may be fatal. The current human case fatality rate is $57 \%$, with death of one patient attributed to multi-organ failure (with interstitial pneumonia) and the remainder to encephalitis. In one of these individuals, the episode of encephalitis that proved fatal had been preceded 13 months earlier by an ILI with meningitis from which he appeared to have made a full recovery (7). Serum obtained during both illnesses was positive for neutralizing antibodies to $\mathrm{HeV}$ as well as for viral genome, and $\mathrm{HeV}$ antigen was identified in brain at necropsy. Relapsing encephalitis may also occur in people infected with the closely related Nipah (NiV) virus (8), the second of only three viruses isolated within the Henipavirus genus. At present it is unclear whether recrudescence of central nervous system (CNS) disease, presumably as a complication of virus persistence in the CNS, is a feature of henipavirus infection in species other than humans. Currently there is no evidence for long-term viral shedding in survivors of Hendra virus infection (9) 


\section{The viral reservoir}

A serological study conducted soon after the discovery of $\mathrm{HeV}$ did not show evidence of neutralizing antibody in the Queensland horse population suggesting that the virus was not being maintained within this species, and so the possibility of another source for the virus was investigated (10). In an initial survey, sera from 46 species including 34 species of fauna were sampled and none were positive for antibody against $\mathrm{HeV}$, but extension of the work to fruit bats (flying foxes) revealed a seroprevalence of over $25 \%$ in these animals (11). There are four species of mainland Australian flying fox, namely the grey-headed flying-fox (Pteropus poliocephalus), black flying-fox (Pt. alecto), little red flying-fox (Pt. scapulatus) and the spectacled flying-fox (Pt. conspicillatus) and there is serological evidence that each harbors $\mathrm{HeV}$. Interestingly, all spillover events to horses have occurred within the natural range of the black flying fox, and transmission from any other flying fox species cannot account for each and every recognized equine infection (Fig. 1A and B) (12).

In free-living bats, $\mathrm{HeV}$ was first isolated from a fetus (Pt. alecto) and a fetus and uterine fluid (Pt. poliocephalus) (13) and subsequently also from urine collected beneath flying fox roosts (14). Although these findings are consistent with systemic infection of flying-foxes by $\mathrm{HeV}$, no associated clinically significant disease has been recognized in them. These observations have been reinforced by experimental studies in Pt. poliocephalus and Pt. alecto $(15,16,17)$, wherein no clinical abnormalities were recorded although sporadic virally-induced vasculitis was identified in some animals, including in the placenta of a pregnant Pt. poliocephalus. Although in these studies $\mathrm{HeV}$ was also reisolated from a fetus and sporadically from pregnant animals, the data overall did not support pregnancy as a significant factor in increasing shedding or transmission opportunity.

Similarly, in a longitudinal field study of the occurrence $\mathrm{HeV}$ RNA in pooled bat urine from under roosts, it was found that shedding varied from year to year, occurred periodically and at any time of the year, and that $\mathrm{HeV}$ was not present in all flying fox colonies all the time (18). These authors also observed that positive findings for $\mathrm{HeV}$ in bat urine did not associate in time with spillover events to horses, consistent with a requirement for other factors to precipitate such transmission. The identity of these factors is currently unknown.

\section{Hendra virus infection in horses}

$\mathrm{HeV}$ infection of horses is believed to be acquired following direct exposure to the virus in flying-fox secretions, however the precise way in which this occurs is not known. The infection is sporadic, commonly involving only a single horse within a group. Occasional multi-horse outbreaks where there is evidence of horse-to-horse transmission - most likely via contamination of surfaces or equipment by infectious fluids - have permitted an estimation of the field incubation period between 4 and 16 days $(1,19,20)$. There is an acute onset of disease, with fever, depression, inappetance, tachycardia, tachypnea, dyspnea, facial edema, aimless pacing, muscle fasciculation, and ataxia: death follows within 48 to $72 \mathrm{hrs}$ in approximately $75 \%$ of cases. In animals which are terminally ill a copious frothy nasal discharge may also be seen as a reflection of severe pulmonary edema. Some affected horses may be found dead. In horses that survive the acute infection clinical recovery may appear 
to be complete but, as the current national policy is to euthanize convalescent horses, no long term follow-up has been carried out on such cases, especially with respect to the potential for recrudescence of virus replication in the central nervous system.

Both neurologic and respiratory signs have been a feature of $\mathrm{HeV}$ infection in horses since the original outbreak in 1994 where, although the dominant clinical presentation was respiratory disease, two convalescent seropositive horses exhibited myoclonic twitches (21). However, in later years the appearance of field cases of acute $\mathrm{HeV}$ infection were even more strongly associated with signs that localized to the respiratory system. Combined with the non-specific nature of many other clinical signs, differential diagnosis - especially from more common disorders such as pneumonia, pleuropneumonia, and colic - was and remains challenging and complex. In contrast to a respiratory syndrome presentation, a multi-horse outbreak developed in an equine referral practice in 2008 where the predominant clinical signs were attributable to involvement of the central nervous system (22). These included ataxia, disorientation, hypersensitivity, head tilt, facial nerve paralysis, stranguria, head pressing, and circling. This outbreak event reinforced the need to also consider $\mathrm{HeV}$ in the differential diagnosis of neurological disease in horses.

Experimental exposure of horses to a $\mathrm{HeV}$ isolate (Hendra virus/Australia/Horse/2008/ Redlands) recovered from the spleen of a horse exhibiting such neurological disease was carried out under Biosafety Level 4 conditions at the CSIRO Australian Animal Health Laboratory, Geelong, Victoria, Australia (23). Clinical signs and pathological findings were generally consistent with those recorded for earlier spillover events, as well as for similar experimental studies conducted using the original $\mathrm{HeV}$ isolate (Hendra virus/Australia/ Horse/1994/Hendra), suggesting that there had been no significant evolution in virus pathogenicity for horses in intervening years. These authors also commented that three of the five horses presenting with neurologic manifestations of acute $\mathrm{HeV}$ infection had preexisting lesions of the head (corneal lesion, nasal granuloma and mandibular fracture), and so there was potential for $\mathrm{HeV}$ exposure in a manner that may have bypassed mucosal protective mechanisms thereby influencing the course of infection.

Moreover, in special consideration of the dominant neurologic manifestations associated with field infection involving Hendra virus/Australia/Horse/2008/Redlands, phylogenetic analysis was conducted on $\mathrm{HeV}$ isolates from horses obtained between 1994 and 2008 (24). Sequence analysis revealed a high level of conservation at both genome and amino acid levels with, in particular, a lower level of nucleotide changes than observed in other RNA viruses and also no correlation between relatedness of isolates and time. Results of assessment of the complete genetic sequence of $\mathrm{HeV}$ recovered from the natural bat host since 2008 are consistent with several virus variants circulating within them at, on occasion, multiple locations over the same time period (14). Overall however, the viral genome appeared to be stable in its reservoir. Interestingly, $\mathrm{HeV}$ isolates recovered from disease outbreaks in horses were genetically aligned to diverse flying-fox virus variants, suggesting that such spillover events are not attributable to the genetic sequence characteristics of a single $\mathrm{HeV}$ variant. 


\section{Pathogenesis and pathology}

In the preclinical stage of infection, viral genetic material can be recovered on nasal swabs from experimental horses after as little as two days post-exposure to $\mathrm{HeV}$ by oral and nasal routes (23). Gene copy numbers in nasal secretions steadily increase through the incubation period and into the clinical phase of infection, consistent with local replication in the upper respiratory tract or nasopharynx. Viremia ensues, followed rapidly by the onset of fever, and soon afterwards viral genome can also be recovered from oral secretions and urine. Signs of systemic illness develop shortly after that as $\mathrm{HeV}$ replication becomes more widely established in tissues and organs.

There is comparatively little pathologic data available from field post mortems and most information has been recorded from experimental studies. In peracute cases there may be few gross abnormalities at post mortem examination. Where described, post mortem lesions in acutely affected animals have included pulmonary edema, congestion and consolidation, with blood-tinged foam in the airways $(1,19,21)$, dilation of subpleural lymphatics (25), subpleural hemorrhage (23), congestion of intra-abdominal lymph nodes (15), and enlarged, edematous submandibular, sternal, and bronchial lymph nodes (23). The dominant light microscopic lesion in both natural and experimental $\mathrm{HeV}$ infection of horses is vasculitis that affects predominantly smaller blood vessels in a wide range of tissues including lung, brain (and meninges), lymphoid tissues, kidney (glomeruli), and female reproductive tract but also nasal mucosa, adrenal gland, liver, heart and gastrointestinal tract. Necrotizing lymphadenitis is common, as is extensive lung involvement including widespread necrotizing alveolitis with marked fibrinous alveolar exudates. Syncytial cells are regularly identified within renal glomeruli, lymphoid tissues, vascular endothelium, lymphatic endothelium, and in alveolar walls. $\mathrm{HeV}$ antigen is readily visualized in affected tissues using appropriate immunohistochemical techniques (Fig 2A and B). Virus may also be recovered from the fresh carcass, especially from lung, kidney and lymphoid tissues but also brain and spinal cord, cerebrospinal fluid, meninges, upper respiratory tract, heart and adrenal gland. As would be expected, delays in post-mortem examination may adversely impact on the success of virus isolation attempts.

A few field cases of $\mathrm{HeV}$ that have clinically recovered from acute disease (associated with the development of virus neutralizing antibodies) have been euthanized in line with current national policy. Each had shown neurological signs during the clinical phase of infection and, at the time of post mortem examination, had mild to moderately severe, focal, nonsuppurative meningoencephalitis with gliosis and perivascular cuffing; low levels of $\mathrm{HeV}$ genome were also recovered from the brain. The significance of these findings with respect to the possibility of virus persistence in the equine brain is not yet understood. However, in the context of potential transmission risk it is relevant to note that infectious virus has not been recovered from human patients with relapsing $\mathrm{HeV}$ (7) or $\mathrm{NiV}$ encephalitis (8).

\section{Laboratory diagnosis}

As the clinical signs associated with $\mathrm{HeV}$ infection are not pathognomonic, laboratory confirmation of the diagnosis is essential. Consideration of the zoonotic potential of the 
virus should guide the process of collection of samples for submission to diagnostic laboratories, and should only be undertaken if the associated risks can be effectively managed. This is especially important because the often peracute nature of the disease is such that results of laboratory testing may not be available until the after the horse has died, meaning that any significant human exposure is likely to have already occurred. In the live horse, samples should include blood in EDTA and nasal, oral and rectal swabs for PCR testing and, if indicated from the PCR result, virus isolation attempts in a BSL4 laboratory. Whole blood should also be collected for serological testing by ELISA or by neutralization test in a BSL4 laboratory (26). Post mortem examination of the recently dead horse is a particularly hazardous activity as the $\mathrm{HeV}$ viral load is highest at this time, but it may be indicated when atypical disease is observed or when confirmation of the diagnosis is essential, for example when a human exposure risk has been identified. Necropsy can be safely conducted by experienced and suitably equipped operators with a predetermined plan and appropriate infrastructure for preventing exposure of personnel, for carcass removal, and for environmental decontamination. However, if those criteria cannot be met then suitable risk reduction measures might include limiting specimen collection to tissues such as the superficial mandibular lymph nodes and a jugular vein blood sample, as well as swabs of nasal, oral and rectal orifices.

Therapy

No specific therapy exists for horses with $\mathrm{HeV}$ infection and, if diagnostic confirmation precedes death, euthanasia is carried out. Appropriate considerations around infection control should guide any welfare interventions in ill horses suspected of being infected by $\mathrm{HeV}$.

\section{Community impact}

The 18 equine $\mathrm{HeV}$ incidents of 2011 and the first reported field infection of a dog were associated with increased national coverage in the mass media, and those communications to the public sent the message that burgeoning infection risk to the community was attributable to expansion of flying-fox populations into urban areas (27) rather than to direct contact with infected horses. As a result, there was increasing pressure to instigate measures for the control or extermination of flying fox populations, in spite of their key environmental role in pollination of native forests and any attendant practical and ethical considerations. Mendez et al (28) also reported increasing numbers of veterinarians and other equine health care staff to be departing equine practice as they believed that they were unable to adequately manage $\mathrm{HeV}$-associated risks and liability within their workplace. Follow-on effects included increased occupational risk for some equine veterinarians, especially practice principals who elected to undertake all the equine work themselves and those veterinarians who elected to work in a less than ideal environment to meet animal welfare needs. A growing level of resentment was also described that was attributed to the fact that some practices would only deliver preventative medicine services to healthy horses. 


\section{A Hendra virus vaccine for horses}

There is no straightforward means of preventing exposure of horses to $\mathrm{HeV}$ that is shed by flying foxes. Factors influencing interspecies transmission are likely complex, are poorly understood, and the interface between bats and horses cannot be eliminated within periurban and rural communities. Thus a more direct approach has been introduced to protect the health of horses and to reduce the risk of human infection, namely vaccination of horses. The aim of suppression of $\mathrm{HeV}$ virus replication in animals exposed to field virus is to remove the acutely ill horse from the chain of onward transmission to people.

$\mathrm{HeV} \mathrm{G}$ attachment glycoprotein is one of the two major envelope glycoproteins that is required for infection of the host cell and, in 2005, Bossart and co-authors reported development of a recombinant soluble $\mathrm{HeV} \mathrm{G}(\mathrm{sG})$ that elicited virus neutralizing antibodies in rabbits (29). A candidate vaccine based on the antigen $\mathrm{HeVsG}$ was first efficacy tested in cats against Nipah virus $(30,31)$ and subsequently in ferrets against $\mathrm{HeV}(32)$, and the success of the outcomes to virus exposure in these species encouraged translation of the work into the horse (33). For use in the horse, $\mathrm{sG}$ was specifically reformulated with a proprietary adjuvant approved for use in that species and delivered as an inactivated subunit vaccine. Data gathered after using a prime-boost immunization regime confirmed development of neutralizing antibody in vaccinated horses, and all immunized horses were protected from disease following exposure to an otherwise lethal $\mathrm{HeV}$ challenge under BSL4 conditions. In addition, there was no evidence of virus replication in vaccinated animals apart from transient low $\mathrm{HeV} \mathrm{N}$ gene copy number detected in the nasal swabs of one horse exposed to virus 6 mos after booster vaccination. However, viral genome was not recovered from the tissues of any horse. More recent serological studies using different vaccination regimes suggest that antibody titer persists at high level 12 mos after a priming series that comprises three immunizations (day 0, day 21, 6 mos); horses exposed to $\mathrm{HeV}$ 12 mos after receiving a third vaccine showed no evidence of $\mathrm{HeV}$ replication in swabs, blood or tissues (Middleton, unpublished observations).

The equine $\mathrm{HeV}$ vaccine (Equivac $\mathrm{HeV}$, Zoetis, Parkville, Vic, Australia) was released for administration by veterinarians late in 2012. As expected vaccine uptake has been greatest in the regions of highest perceived risk, notably coastal Queensland and northeastern NSW but, as $\mathrm{HeV}$ events are sporadic, it may be some time before the impact of vaccination on the incidence of acute $\mathrm{HeV}$ infection of horses can be assessed. Complete $\mathrm{HeV}$ vaccine coverage of the Australian horse herd will not be achieved for several reasons, including the cost of its administration and varying perceptions around which horse populations are at risk of disease. Accordingly, improved infection control procedures and a heightened awareness of the possibility of $\mathrm{HeV}$ infection will need to be maintained for dealing with sick horses, particularly when $\mathrm{HeV}$ vaccination status is uncertain.

\section{Post exposure therapeutics for people}

Exposure of humans to infectious doses of $\mathrm{HeV}$ from acutely affected horses may occur in the future. Not all horses will be vaccinated against $\mathrm{HeV}$ and outbreaks occur in temperate to tropical climates where continual compliance with certain items of personal protective 
equipment (PPE) may be difficult to achieve. The emotional attachment of humans to their horses leads to regular close contact where use of PPE is usually impractical, and the occupational exposure limits by contact and/or inhalation are, and will remain, unknown. In 2008, Zhu and co-authors screened a large non-immune human antibody library and described the identification and characterisation of a human monoclonal antibody, m102.4, which neutralized $\mathrm{HeV}$ and Nipah virus in vitro (34). When given post-exposure to laboratory animals, m102.4 has been shown to prevent acute Nipah and Hendra -associated morbidity and mortality in ferrets (35, Middleton unpublished observations) and in African Green monkeys (36), although infection is not prevented. In addition, amelioration of disease signs in both species is optimal when m102.4 is administered within $24 \mathrm{hrs}$ of exposure to virus, prior to the detection of Hendra viral RNA in blood or its recovery from oropharyngeal secretions, and before the onset of fever or other clinical signs (36, Middleton unpublished observations).

These studies encouraged the initiation of preclinical safety testing of m102.4 and a Phase 1 human clinical trial that will commence in 2014. However, the value of m102.4 in management of human infection after the onset of clinical illness, especially the complication of encephalitis, is yet to be assessed.

\section{Other susceptible animal hosts}

Diverse species have proved susceptible to $\mathrm{HeV}$ infection under experimental conditions including cats, ferrets, hamsters, pigs, and guinea pigs. Each exhibits disease generally similar to that observed in horses, with ferrets and hamsters in particular used in efficacy assessment of anti-henipavirus vaccines and therapeutics $(37,38,39,40)$. More recently, Dups et al (41) reported encephalitis in wild-type laboratory mice in the absence of significant systemic infection; this model holds great promise as a tool for investigation of the neurological complications of $\mathrm{HeV}$ infection that are a particular feature of the human disease. Field infections have not yet been recorded in pigs, cats or guinea pigs (ferrets are not permitted as pets in Queensland), but during 2011 a dog sampled on an outbreak property was found to have antibody to $\mathrm{HeV}$ without having shown signs of disease. A similar canine case was identified in NSW in 2013 during investigation of the $\mathrm{HeV}$ associated death of a horse.

In order to better assess the impact of $\mathrm{HeV}$ infection in dogs and their potential for transmission risk, dogs were exposed to $\mathrm{HeV}$ under BSL4 containment conditions (Middleton, unpublished observations). Dogs proved to be reliably susceptible to infection under the conditions of exposure, and showed only subtle or no clinical signs of illness; development of neutralizing antibody was associated with virus clearance. Virus replication in the pharynx led to shedding of infectious virus that, for a short period of time, was sufficient to transmit infection to naïve ferrets. As yet, all human cases of $\mathrm{HeV}$ infection have had a strong epidemiological connection to close contact with an infected horse. The level of risk posed by field exposure to $\mathrm{HeV}$-infected dogs has not yet been ascertained. 


\section{Summary}

The incidence of emerging zoonotic diseases has been increasing for several decades (42), and significant predictors of emergence such as increasing human population growth and density will persist in the foreseeable future. Thus it is to be expected that further new and highly pathogenic infections will enter the human population, that companion or agricultural animals may be the immediate source, and a wildlife species will prove to be the pathogen's reservoir host. As for Hendra virus, mitigating the impact of such events on the community will require ongoing acknowledgement of the interconnectedness of human, animal, and environmental health that is harnessed to interdisciplinary approaches to management of disease outbreaks, definition of knowledge gaps, and prioritization of research needs.

\section{Acknowledgments}

\section{Funding sources:}

Dr Middleton: NHMRC, NIH, Commonwealth of Australia, Queensland State Government, Intergovernmental Hendra Virus Taskforce

\section{References}

1. Murray K, Selleck P, Hooper P, et al. A morbillivirus that caused fatal disease in horses and humans. Science. 1995; 268:94-97. [PubMed: 7701348]

2. Chua KB, Goh KJ, Wong KT. Fatal encephalitis due to Nipah virus among pig-farmers in Malaysia. Lancet. 1999; 354:1256-1259.

3. Marsh GA, de Jong C, Barr JA, et al. Cedar Virus: A novel Henipavirus isolated from Australian bats. Plos Pathogens. 2012; 8:e1002836. [PubMed: 22879820]

4. Symons R. Re: Canine case of Hendra virus and Hendra virus vaccine. Aust Vet J. 2011; 89(10):N24.

5. [Accessed March 14, 2014] Hendra Virus, equine - Australia (18): (Queensland) canine. http:// www.promedmail.org ProMed Arch No: 20130721.1837123

6. Playford EG, McCall B, Smith G, et al. Human Hendra virus encephalitis associated with equine outbreak, Australia. Emerg Infect Dis. 2008; 16(2):219-23. 2010. [PubMed: 20113550]

7. O'Sullivan JD, Allworth AM, Paterson DL, et al. Fatal encephalitis due to novel paramyxovirus transmitted from horses. The Lancet. 1997; 349:93-5.

8. Tan CT, Goh KJ, Wong KT, et al. Relapsed and late-onset Nipah encephalitis. Ann Neurol. 2002; 51:703-8. [PubMed: 12112075]

9. Taylor C, Playford EG, McBride WJ, et al. No evidence of prolonged Hendra virus shedding by 2 patients, Australia. Emerg Inf Dis. 2012; 18:2025-7.

10. Young PL, Halpin K, Selleck PW, et al. Serologic evidence for the presence in Pteropus bats of a paramyxovirus related to equine morbillivirus. Emerg Inf Dis. 1996; 2:239-40.

11. Field H, Young P, Yob JM, et al. The natural history of Hendra and Nipah viruses. Microbes Infect. 2001; 3:307-314. [PubMed: 11334748]

12. Hutson, T.; Suyanto, A.; Helgen, K., et al. [Accessed 07 February 2013] Pteropus alecto. IUCN 2013. IUCN Red List of Threatened Species. Version 2013.2. 2008. <www.iucnredlist.org>

13. Halpin K, Young PL, Field HE, et al. Isolation of Hendra virus from pteropid bats: a natural reservoir of Hendra virus. J Gen Virol. 2000; 81:1927-1932. [PubMed: 10900029]

14. Smith I, Broos A, de Jong, et al. Identifying Hendra virus diversity in Pteropid bats. PLoS One. 2011; 6:e25275. [PubMed: 21980413]

15. Williamson MM, Hooper PT, Selleck PW, et al. Transmission studies of Hendra virus (equine morbillivirus) in fruit bats, horses and cats. Aus Vet J. 1998; 76:813-818. 
16. Williamson MM, Hooper PT, Selleck PW, et al. Experimental Hendra virus infection in pregnant guinea-pigs and fruit bats (Pteropus poliocephalus). J Comp Path. 1999; 122:201-207. [PubMed: 10684689]

17. Halpin K, Hyatt AD, Fogarty R, et al. Am J Trop Med Hyg. 2011; 85:946-951. [PubMed: 22049055]

18. Field H, de Jong C, Melville D, et al. Hendra virus infection dynamics in Australian fruit bats. PLoS One. 2011; 6:e28678. [PubMed: 22174865]

19. Selvey LA, Wells RM, McCormack JG, et al. Infection of humans and horses by a newly described morbillivirus. Med J Aust. 1995; 162:642-645. [PubMed: 7603375]

20. Baldock FC, Douglas IC, Halpin K, et al. Epidemiological investigations into the 1994 equine morbillivirus outbreaks in Queensland, Australia. Singapore Vet J. 1996; 20:57-61.

21. Rogers RJ, Douglas IC, Baldock FC, et al. Investigation of a second focus of equine Morbillivirus infection in coastal Queensland. Aust Vet J. 1996; 74:243-4. [PubMed: 8894043]

22. Field H, Schaaf K, Kung N, et al. Hendra virus outbreak with novel clinical features, Australia. Emerg Infect Dis. 2010; 16(2):338-340. [PubMed: 20113576]

23. Marsh GA, Haining J, Hancock TJ, et al. Experimental infection of horses with Hendra virus/ Australia/Horse/2008/Redland. Emerg Infect Dis. 2011; 17:2232-8. [PubMed: 22172152]

24. Marsh GA, Todd S, Foord A, et al. Genome sequence conservation of Hendra virus isolates during spillover to horses, Australia. Emerg Infect Dis. 2010; 11:1767-9. [PubMed: 21029540]

25. Hooper PT, Ketterer PJ, Hyatt AD, et al. Lesions of experimental equine morbillivirus pneumonia in horses. Vet Pathol. 1997; 34:312-22. [PubMed: 9240840]

26. [Accessed March 14, 2014] Guidelines for veterinarians handling potential Hendra virus infection in horses Version 5.0. 2013. Available at: http://www.daff.qld.gov.au/_data/assets/pdf_file/ 0009/97713/2355-guidelines-for-veterinarians-sept-2013.pdf

27. Degeling C, Kerridge I. Hendra in the news: public policy meets public morality in times of zoonotic uncertainty. Soc Sci Med. 2013; 82:156-63. [PubMed: 23294874]

28. Mendez DH, Judd J, Speare R. Unexpected result of Hendra virus outbreaks for veterinarians, Queensland, Australia. Emerg Inf Dis. 2012; 18:83-5.

29. Bossart KN, Crameri G, Dimitrov AS, et al. Receptor binding, fusion inhibition and induction of cross-reactive neutralizing antibodies by a soluble G glycoprotein of Hendra virus. J Virol. 2005; 79(11):6690-6702. [PubMed: 15890907]

30. Mungall BA, Middleton D, Crameri G, et al. Feline model of acute nipah virus infection and protection with a soluble glycoprotein-based subunit vaccine. J Virol. 2006; 80:12293-302. [PubMed: 17005664]

31. McEachern JA, Bingham J, Crameri G, et al. A recombinant subunit vaccine formulation protects against lethal Nipah virus challenge in cats. Vaccine. 2008; 26:3842-52. [PubMed: 18556094]

32. Pallister J, Middleton D, Wang LF, et al. A recombinant Hendra virus G glycoprotein-based subunit vaccine protects ferrets from lethal Hendra virus challenge. Vaccine. 2011; 29:5623-30. [PubMed: 21689706]

33. Middleton D, Pallister J, Klein R, et al. Hendra virus vaccine, a one-health approach to protecting horse, human, and environmental health. Emerg Inf Dis. 2014; 20:372-9.

34. Zhu Z, Bossart KN, Bishop KA, et al. Exceptionally potent cross-reactive neutralisation of Nipah and Hendra viruses by a human monoclonal antibody. J Infect Dis. 2008; 197:846-853. [PubMed: 18271743]

35. Bossart KN, Zhu Z, Middleton D, et al. A neutralizing monoclonal antibody protects against lethal disease in a new ferret model of acute Nipah virus infection. PLoS Path. 2009; 10:e1000642.

36. Bossart KN, Geisbert TW, Feldmann H, et al. A neutralizing human monoclonal antibody protects African green monkeys from Hendra virus challenge. Sci Transl Med. 2011; 3:1-17.

37. Hooper PT, Westbury HA, Russell GM. The lesions of experimental equine morbillivirus disease in cats and guinea pigs. Vet Pathol. 1997; 34:323-29. [PubMed: 9240841]

38. Westbury HA, Hooper PT, Brouwer SL, et al. Susceptibility of cats to equine morbillivirus. Aust Vet J. 1996; 74:132-134. [PubMed: 8894019] 
39. Guillaume V, Wong KY, Looi RY, et al. Acute Hendra virus infection: analysis of the pathogenesis and passive antibody protection in the hamster model. Virology. 2009; 387:459-65. [PubMed: 19328514]

40. Li M, Embury-Hyatt C, Weingartl HM. Experimental inoculation study indicates swine as a potential host for Hendra virus. Vet Res. 2010; 41:33. [PubMed: 20167195]

41. Dups J, Middleton D, Yamada M, et al. A new model for Hendra virus encephalitis in the mouse. PLoS One. 2012; 7:e40308. [PubMed: 22808132]

42. Jones KE, Patel NG, Levy MA, et al. Global trends in emerging infectious diseases. Nature. 2008; 451:990-3. [PubMed: 18288193] 


\section{Key points}

- Hendra virus infection is a serious emerging zoonosis, and human infection is acquired through contact with acutely infected horses

- The natural reservoirs of Hendra virus are Australian mainland flying-foxes, and horses are infected following exposure to flying fox secretions

- The increasing number of equine outbreaks and associated human risk exposures exacerbate community concerns and heighten pressure to cull flyingfox populations

- Use of an inactivated Hendra virus subunit vaccine in horses reduces the potential for virus replication and thus the risk of transmission of infection to people

- Improved infection control procedures and a heightened awareness of the possibility of Hendra virus infection will need to be maintained for dealing with sick horses, particularly those whose vaccination status is uncertain. 


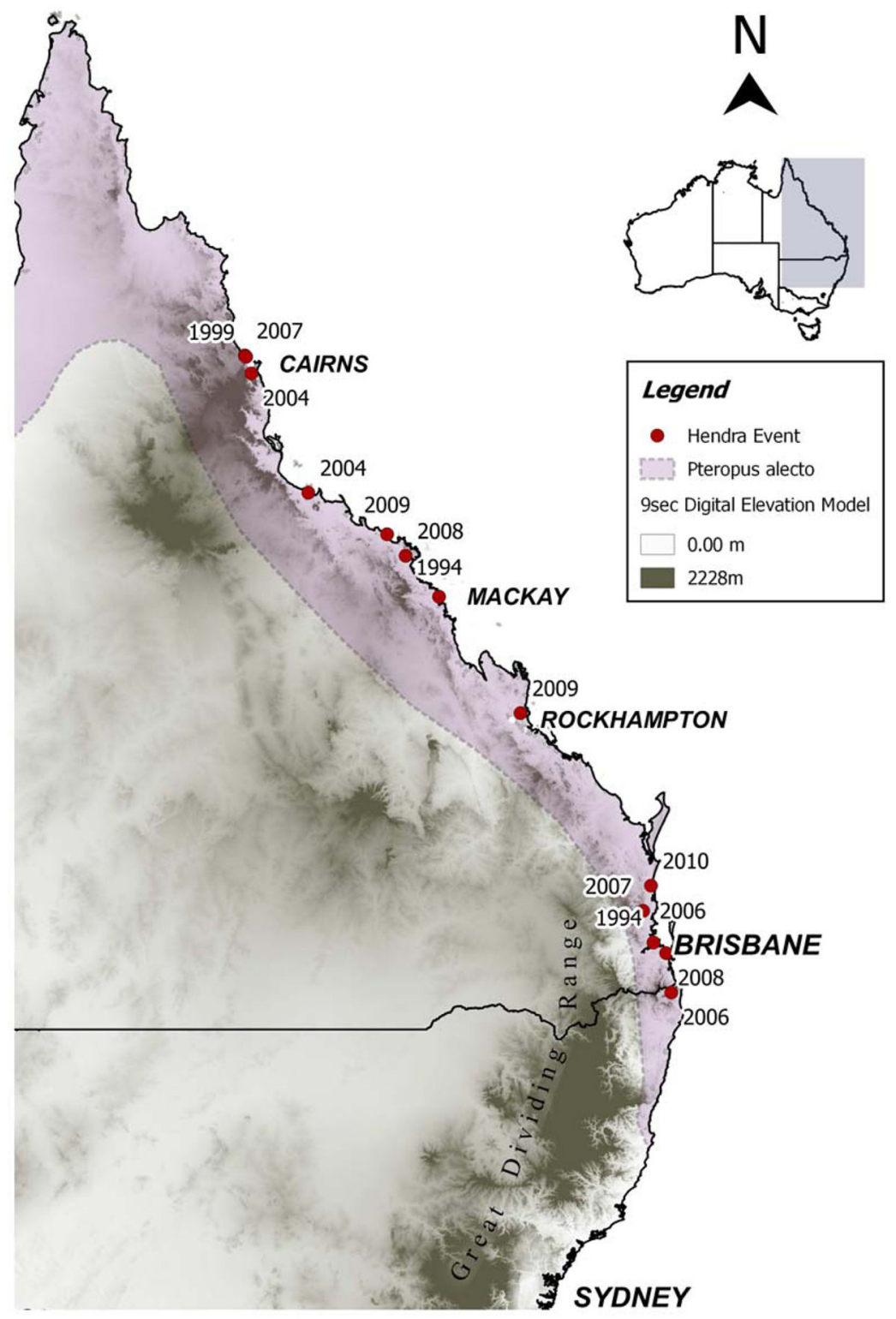

Vet Clin North Am Equine Pract. Author manuscript; available in PMC 2015 December 01. 


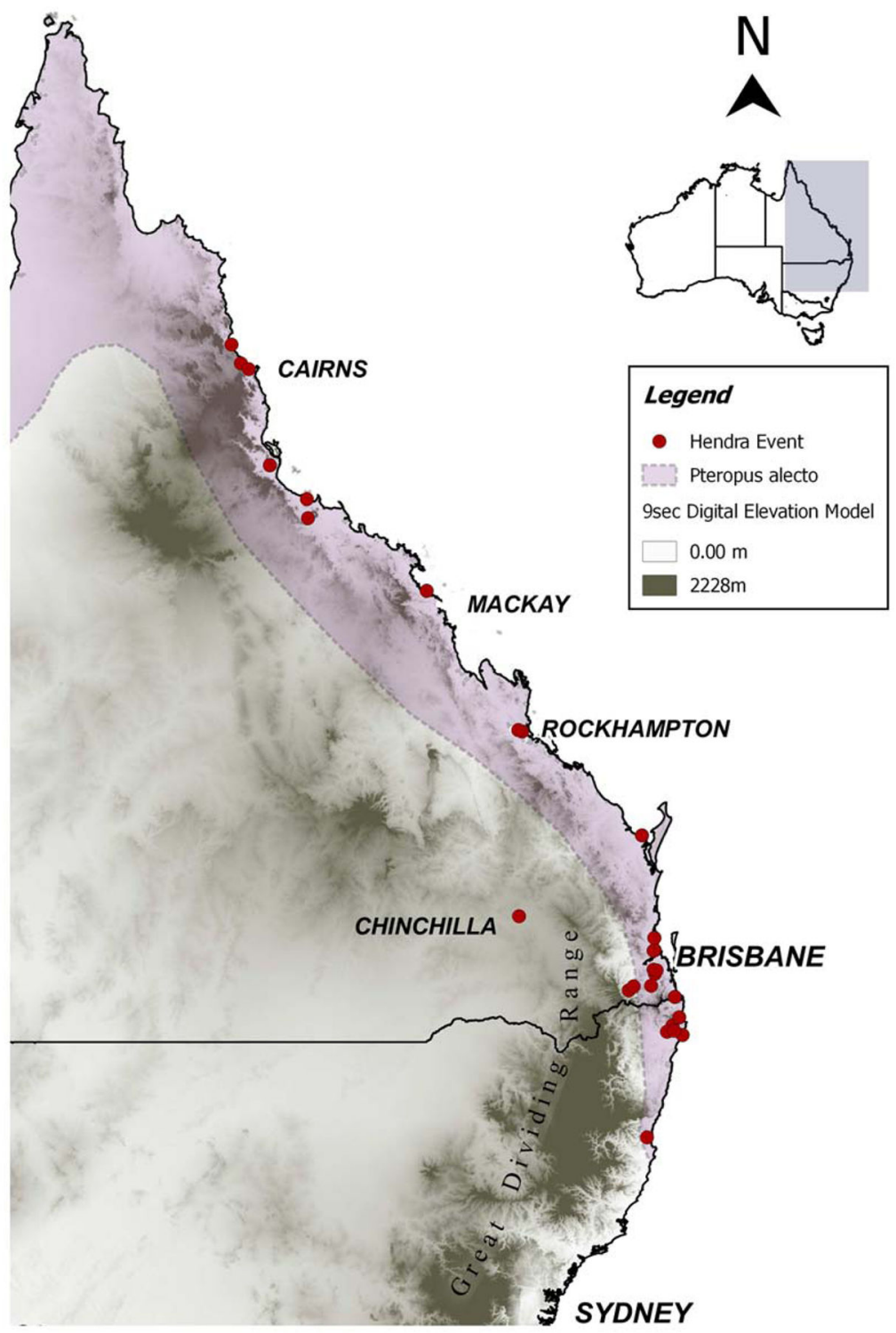

Figure 1.

Figure 1A: Locations of HeV events between 1994 and 2010, highlighting the distribution of Pt. alecto and the low lying coastal regions on the $9 \mathrm{sec}$ digital elevation model.

Figure 1B: Locations of HeV events between 2011 and 2013, highlighting the distribution of Pteropus alecto, the low lying coastal regions on the $9 \mathrm{sec}$ digital elevation model and Chinchilla, the first case west of the Great Dividing Range 

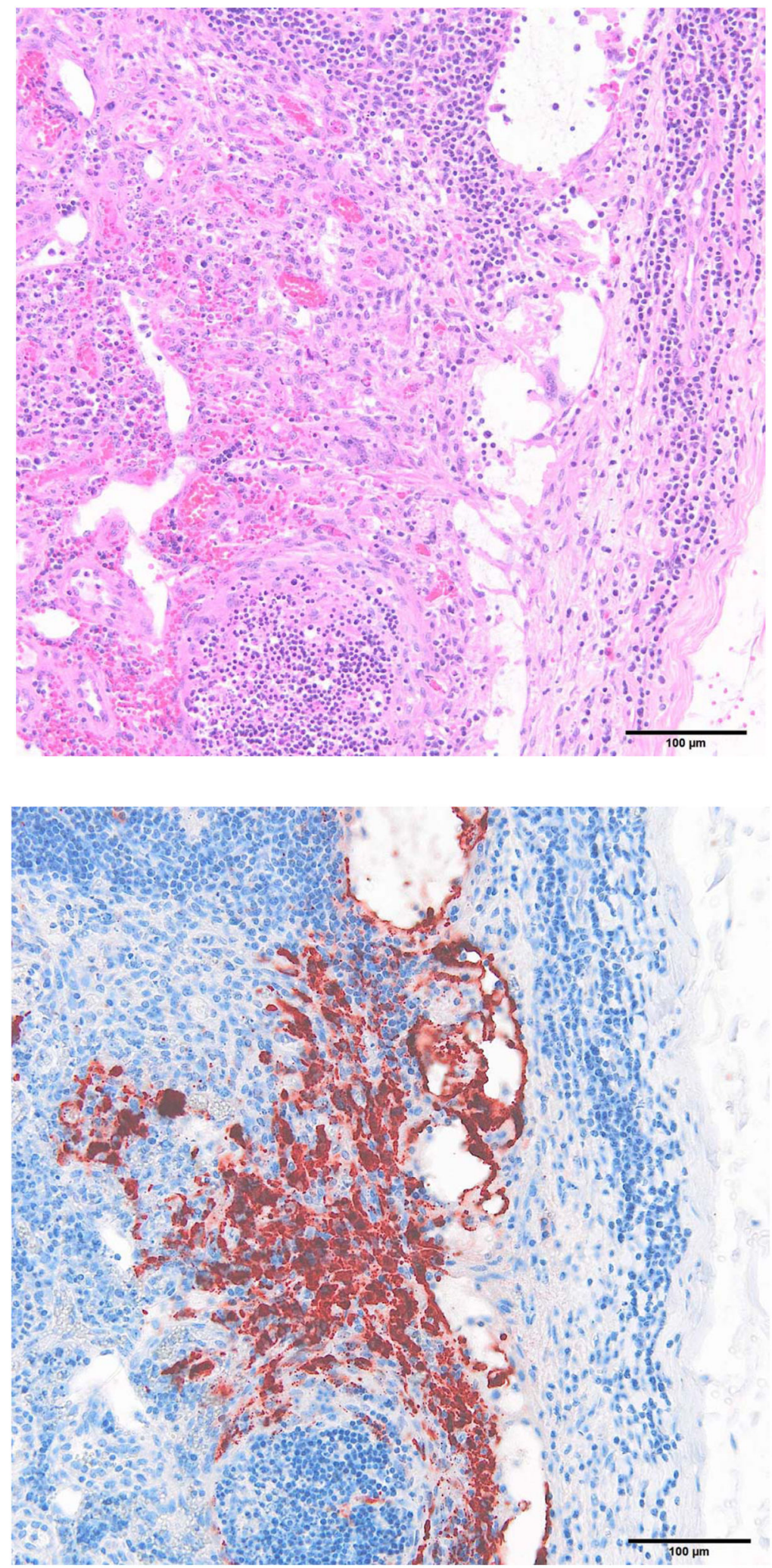

Figure 2. 
Figure 2A: Histological section of lymph node from horse with acute $\mathrm{HeV}$ infection showing lymphadenitis with syncytial cell formation. HE

Figure 2B: HeV antigen in section adjacent to Fig 2A. Anti-Nipah N antibody. 